\title{
Image-based Digital Marketing
}

\author{
Shyam R. Sihare \\ Faculty of Computer Science and Application, Dr. APJ Abdul Kalam Govt. College, Silvassa-396230, India \\ Email:shyams_sihare1979@rediffmail.com
}

Received: 27 May 2017; Accepted: 07 July 2017; Published: 08 September 2017

\begin{abstract}
An image represents millions of words which is depend on people interpretation. If image application considers for the marketing arena, then it represents to masses of peoples of different categories as per their requirements. The image-based marketing is an innovative and creative phenomenon which highly depends on geographical areas as well as on the interest of different placed habitat consumers. At recent times, the digital devices are widespread and it possesses by common peoples for completion of their daily miscellaneous needs and services. That is why, a new globe is opened for digital marketing, especially imagebased marketing. Marketers jolt out traditional marketing strategies and adopt new marketing strategies to enhance productivity and sale. However, it is possible by application of a digital communication medium due to its effectiveness and efficiency. At recent times, the marketing paradigm has been shift very rapidly as per consumer mindset, for that, it is essential to switch into modern marketing technique keeping in mind of future firm prospect and its prosperity. Hence, in this research article, we discuss of how product sale grows by adopting digital marketing strategies, with that, we analyzed consumer behavior.
\end{abstract}

Index Terms - Image-based marketing, traditional marketing, marketers, digital marketing

\section{INTRODUCTION}

In recent times, the scenario of digital marketing almost changed as per likeness, association, ambush, call to action and close range marketing which is played significant roles; even these are motivating elements for digital marketing. The application of digital devices is commonplace, with that, most of the digital device holder use internet for the completion of daily job [1-3]. On such condition, image-based marketing has played significant roles on every sector. Here, every sector means online shopping site, online booking, shopping mall, online reservation etc. However, the digital marketing is completely different than traditional marketing in respect of marketing strategies. In a digital marketing, first of all, analyze potential customer requirements and interest and collect information by specific survey mechanism (i.e. questionnaires, feedback, on-site observation, conducting a different type of interview with customers etc). On the basis of collected data, make a planning of digital marketing, and at last, make an image-based design layout. However, on a regular interval, it is essential to analyze the digital marketing content and modified as per customer requirements and interest, in other words, it is called as maintenance [4-9].

Due to internet data speed improvement, different social sites platform (i.e. Facebook, Instagram, Pinterest, Tumblr etc) has emerged to provide services to consumers. These social sites platform played a significant role to shift traditional marketing paradigm as e-marketing paradigm. Hence, traditional marketing has been completely changed as electronic marketing (i.e. eimage, e-mail, e-content, e-commerce, e-tailing etc). Among these electronic marketing elements, e-image marketing can be placed on a top because it is easily interpreted by the potential customer. A customer easily understands the product details if we placed product image in an attractive form instead of text form. In a modern world, there has no time to read all information regarding a particular product, a customer wants to know about product very easily by image instead of consuming too much time for collecting textual information [10].

Modern consumers used different digital tools, that digital tools make a guide to product seekers for making a concrete conclusion for product procurement. When we look at different digital marketing, image-based product marketing can be placed on a significant position than others electronic marketing strategies and planning. It would be inappropriate to endorse every product as in textual form in modern lifestyle world.

A consumer searches a particular product, which they want by image-based analysis and considered its brand before procurement. However, a product image should need following requirements to make access as in convenient ways for the common consumers which they used the common handheld electronic devices:

1) The images should be feasible with any types of handheld electronic devices.

2) The images should be in high resolution instead of stick to display constraints.

3 ) If required, most of the images should be in high definition (HD) form.

4) The images should be as eye-catching. That is, it is in an attractive form.

5) The images should be as easy to download format on any handheld devices. 
6) Display those product images which actually want by consumers. Dummy images and virtual images would be harmful for enhance sale.

7) On need, combine short HD video with HD images for attract consumers towards the products.

When deal with leading social media platforms for digital marketing (i.e. Facebook, Instagram, Pinterest, Tumblr etc), we must know about customer interest by analysis of his interest or disinterest, after analysis, display those product images which shows interest throughout login session on opened webpage. Different social media platforms available nowadays, however, in recent times, Facebook is commonly used social media by most of handheld devices users. Most of the income has been incurred (over $\$ 2.68$ billion) by Facebook through advertisement as compared to others social media platforms (fig. 1). Generally Facebook used image-based marketing by creating of different Facebook pages. However, on this period emerged different social media sites which act as competitor of Facebook; Instagram, Pinterest, Tumblr are some example which attract by consumers as well as by marketers for imagebased marketing.

In recent studies showed that Instagram post looked by the most of users after Facebook images post looked by users. In another term, Instagram is the competitor of Facebook regarding of image-based digital marketing. More than three times consumers have been perceived the Instagram post when compared with the Facebook equivalent post. The following metrics are gathered to make comparative study of two social media sites:

- Facebook post -6 billion "active" (like, comments, or shares)

- Instagram post - 3.4 billion "active" (like, comments)

- Facebook - 2,396 actions per post

- Instagram - 6,932 actions per post

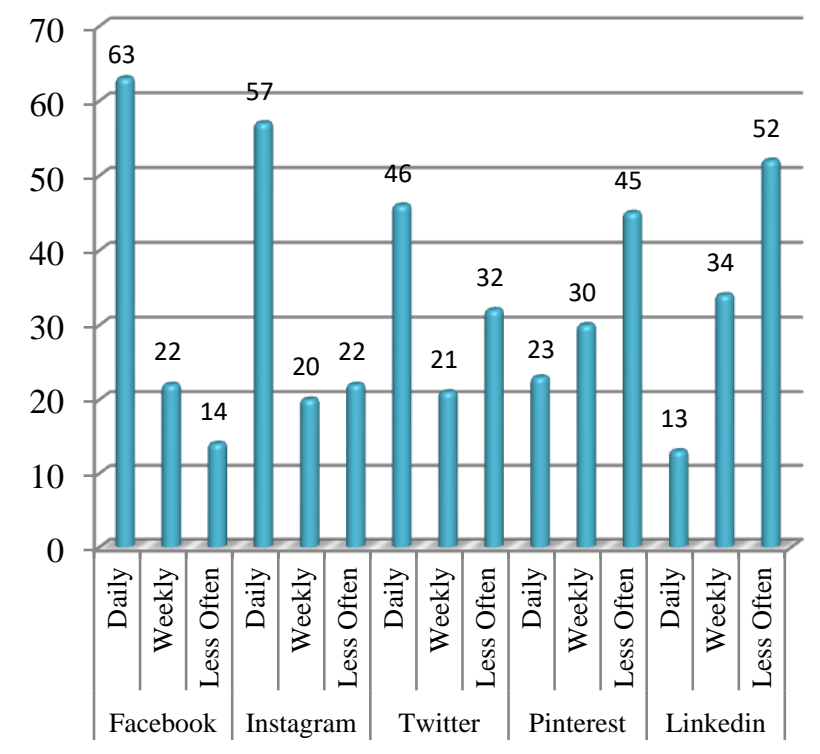

Fig.1. Frequency of social media used by the users
If image-based marketing would place in the social media then digital marketing strategies has been changed completely, effect of this, consumers would adopt this with the positive response. Furthermore, it would also possible in near future that the image-based marketing will dominate to the others digital based marketing since product images are more reliable and mind pleasure. The reason behind is that, a presence of active respondent is more than the passive respondent at this time.

If endorsed a product by the image-based marketing then product sale rate would be enhanced. For this, need proper planning for proper utilization of social media and others digital media.

\section{ONLINE SHOPPING PORTAL}

As optimum way of images are used can be looked into different online shopping portal. In India, there are numerous online shopping portals, in recent times it is boomed. A few Indian online shopping portals are Homeshop18, Shopclues, Snapdeal, Myntra, Trendin, Jabong, Rediff, Flipkart, Amazon and much more. Most of the e-commerce sites have been used images for attracting consumers and that image attraction can be converting into buyers in future. Not only images are used by the e-commerce sites but audio, video clipped also used to know about the product detail by the common peoples. However, the following points keep always in a mind while uploading an image in an online shopping portal:

- The images should not be too large.

- The images should be arranged in horizontal or vertical or grid form for proper utilization of web page.

- The images should be in an attractive form by using different color pattern by keep blank background. That is, background must be white or none for real reflection of product images; image background and foreground should be the complement to one another.

- Keep minimum textual information with the images.

- Images should be arranged as in catalog way for consumer convenience in order to make search easy by millions of images.

- The images should not be restricted for particular devices architecture and operating system. Images should be platform independent, hardware architecture independent as well as web browsers independent.

- Images should upload as in JPEG format because it takes minimum storage as compared to others images file format (i.e. tiff, .bmp, .gif, .pnf etc)

- For video, video duration should be too short (maximum one minutes video would be sufficient for product marketing).

The above are very few points regarding image-based marketing, lots of points should be kept in a mind while 
uploading audio, video, audio-video or images on online shopping portals. The sample of image-based marketing layout is shown in fig. 2 which is taken from Flipkart online shopping portal.

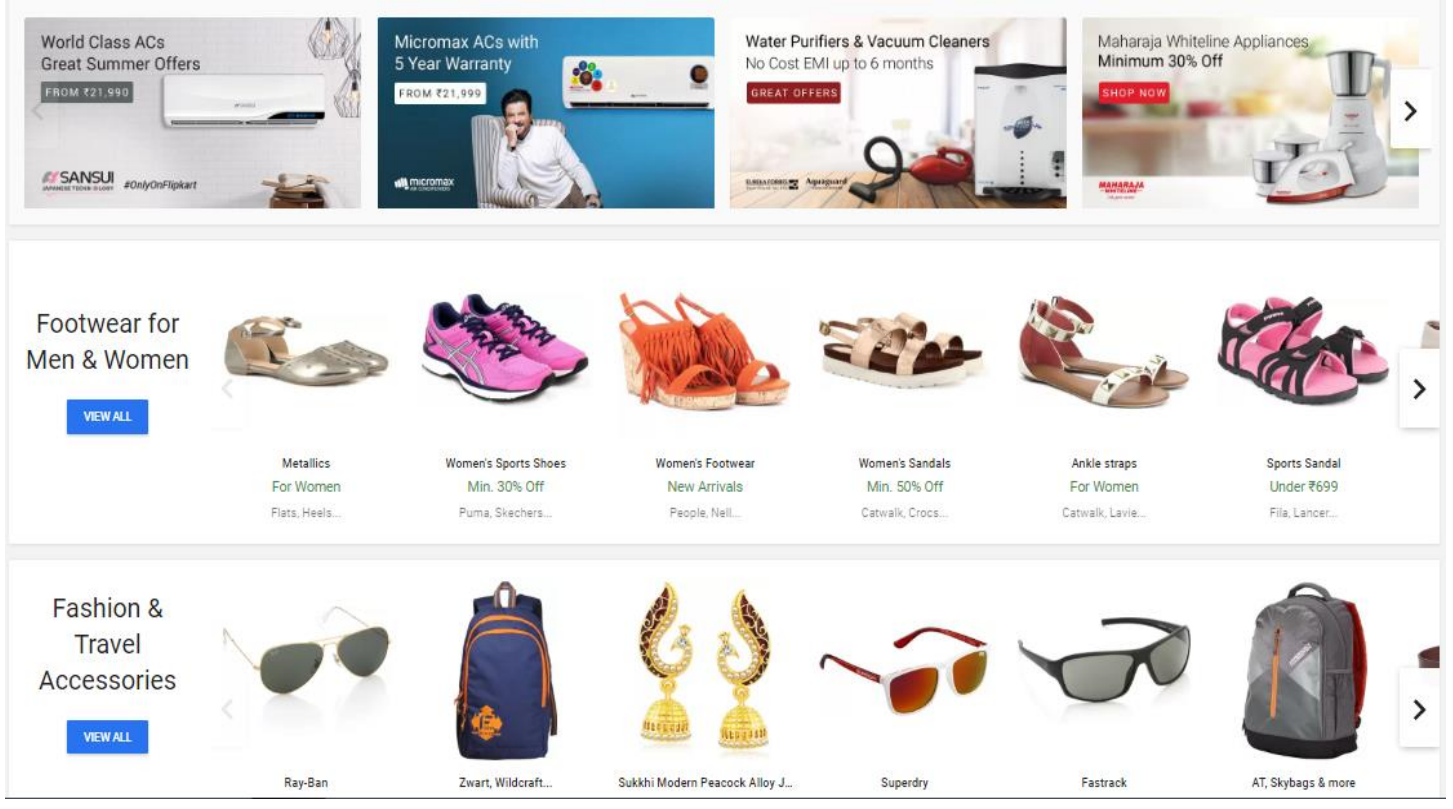

Fig.2. Image-based marketing in online shopping portal (Courtesy of Flipkart.com)

\section{IMAGE-BASED MARKETING IN MiscelLANEOUS PORTAL}

Not only online shopping portal used the images for marketing but also different e-commerce related web portals have been used the images for their products marketing as in digital forms. A few examples are Online Hotel Booking, Railways Reservation, Airlines Reservation, Online Bus Booking etc. As we know, images are used in every webpage so that the customer feels comfortable and the webpage looks attractive. Most of the decision of customers is depends by analysis of digital images. Hence, we cannot skip digital images in any e-commerce web portals. The fig. 3 is an example of this which is taken from the Yatra.com e-commerce web portal.

\section{A. Make online tourist place}

The tourism is an emerging sector because people connected one another through telecommunication medium and get more information about different places. At recent times not only intra-country tourism flourished but inter-country tourism also flourished. When we make a comparative study about tourism then intra-country tourism flourished more as economic way. However, without the internet it could not be complete because through the internet it is easy to reach any place just clicks a button. Hence, every tourist place has been connected by internet. And most of the tourist gets help from the internet to know more about that location where they make planned to visit. They want maximum information without lots of content reading. On such condition, the image-based marketing of tourist placed plays significant roles. However, the following point should keep in a mind while uploading images of the tourist places and surround of it:

- Images should be in 3D to get more information about tourist places within a fraction of the time.

- Images should be captured by the high-resolution camera.

- Not only specific places images upload but also surrounding site-seeing places images should be placed.

- If need, a segment of the respective place map should be placed with the site-seeing places to get rough ideas instantly.

- Tourist places should be connected with nearest hotel booking system to avoid inconvenience by tourists; such facility also placed with online siteseeing portals.

- Upload rail route images to know more about those places, through that feel comfortable by tourist.

\section{B. Role of images during teaching-learning process}

One image speaks thousands of words, this is the Chinese proverb. The image-based teaching-learning process is more effective than content-based to clear complex concept very quickly among a mass of audience. Hence, lots of images placed in small child textbook irrespective tons of content. With that include audiovideo clip by which complex concept make interesting even slow learner students. Hence, image-based marketing has wide scope in teaching-learning mechanism. The following are advantages when include images during teaching-learning process:

- Keep concept long-lasting in a mind 
- Quickly understand a concept by correlating with previous knowledge which being exist in a mind.

- Easily correlate with existing surrounding and mold the society as per image-based ways.

- Mind understanding capacity grows rapidly and makes analysis, decision, and design very quickly. In short, through this accelerate creativity.

The following point should keep in a mind during teaching-learning process:

Keep maximum animation instead of images.

- Make image-based teaching as per student age, grasping capability, mentality toward the subject, sex, surrounding and culture.
- Include minimum textual information with images.

- Select appropriate images by consider of student understanding level.

\section{Online Real Estate System}

The real estate can upload different angles internal as well as external land/house layout images. Every image should be linked to know further information relevant of that. The real estate portal should upload attractive images on a cover page. The 3D house images would appropriate choice to attract buyers to buy houses/flats/apartments.
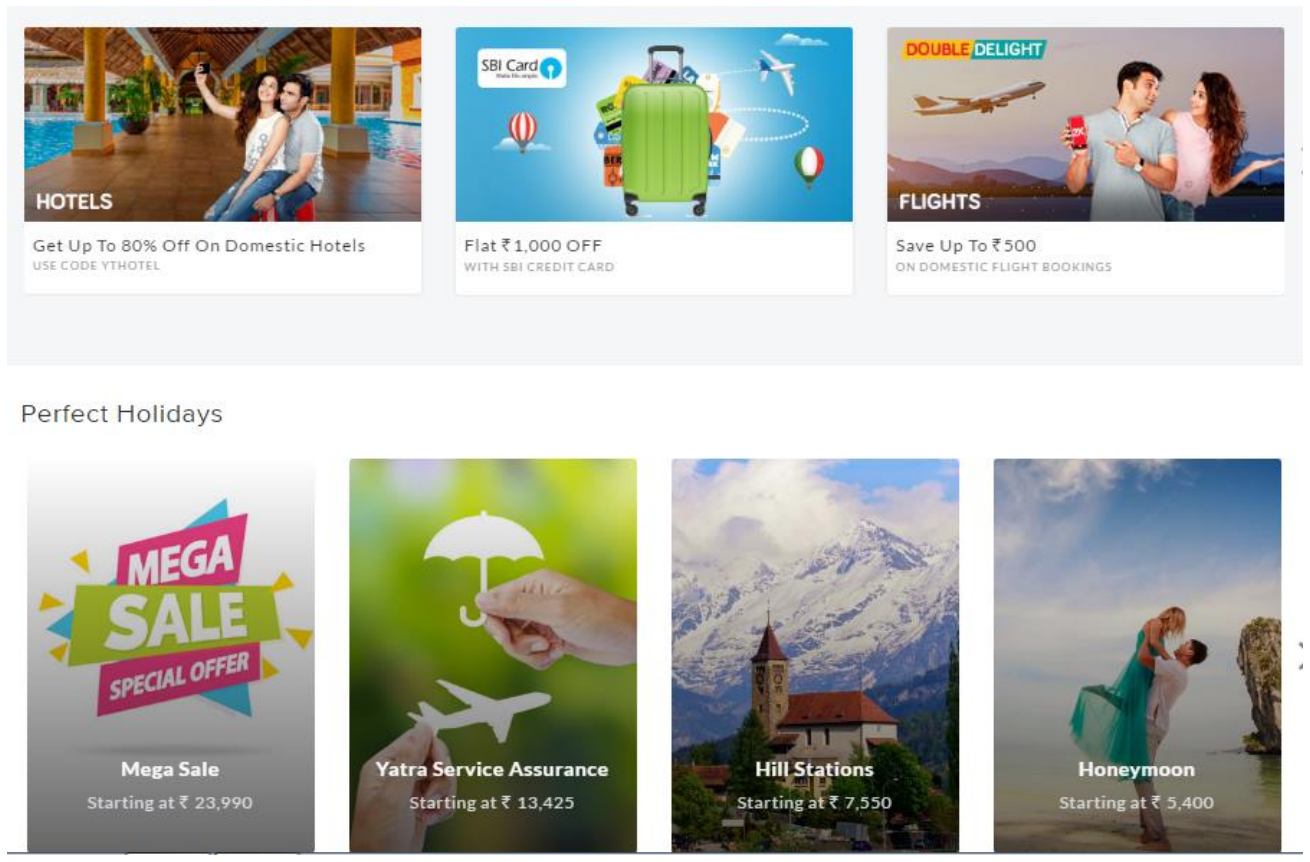

Fig.3. Image-based marketing sample layout in miscellaneous web portal (courtesy of yatra.com)

\section{ObJective(S) Of Research}

The following few points are more worthwhile while studying the image-based marketing for growing of product sale rate of a company:

- Good images attract consumers, effect of this, support to grow sales whereas poor images work opposite of this.

- When image format is in inappropriate format, then image will act as a counterproductive. As a result, the consumer will be discouraged about that product and will never visit that e-commerce web portal.

- Image selection highly depends on consumer requirements and their interest. For this, data should be collect about like and dislike image pattern and make analysis, after that design image as per his/her requirements and at last upload them on e-commerce web portals, keep them until further clarification has not been received from the potential consumers.

- Make differentiate between potential customers and actual customers and make a plan of image design as per both of interest and requirement. Similarly, while designing of images for marketing then the images should be accurate for attract both of customers.

- The image-based marketing offers high visibility. The consequence of this, there is no more problems would create to the customer to search intended products details. Customers can easily search an intended product and if feel comfortable with the image then without reading of the tons of content, they make an online demand to purchase those products. As such response comes from most of the consumer then your company image marketing is in an attractive form, hence, very soon, your product brand will be endorsed among the customer world. 
- In recent times, customers want to look product physically with the help of images; hence, an image should be in an attractive form because it is today's demand. Modern customers are not interested to read the content of the product; they mostly make a decision without deeply reading of product details. However, an image should have a hyperlink and in a hyperlink mentioned product details in textual forms because a few customers want to know more about that product which they want to purchase in a future and at present.

- By looking on images by intended customers quickly makes a decision and click on the advertising images. On clicking of the images means indirectly make advertising that product by adding it in eyes of Google. It generates traffic of the intended website and adds into Google eyes. Hence, image-based marketing grows quickly which is hard to determine.

- Customers can also connect with videos for the various motives. Videos play significant roles for communicating with consumers. It inviting to the customers for more study about the company brand. We can engage the consumers by offering them the product brand videos. Furthermore, the video makes the influence on the mind of customers; hence, a customer wants to know more about products.

- The process of describing images and video stories is an important part. They are the fastest and efficient means for communicating with customers

\section{LITERATURE REVIEW}

Image-based marketing works as a medium to communicate with interested customers quickly and effectively. An average human being makes few second attentions on an image, in a fraction of the second; image should make highly impact over his mind. Hence, visual content let him know about brands within that few second. That is, a company should be focused on brand image and distributes them among customers in such way by which customer easily interpret within a few second and make a judgment on the products [11].

The [12] has stated e-model where different types of models introduced such as online revenue models, intermediary model, attribution model, communication model, customer model etc. Through models make emarketing strategies keep centric the potential customers. After that, make focused on social media marketing strategies for endorsement of products and how to design the e-commerce web portals they guide about all these.

The email and mobile marketing is the potential medium for marketing in effective ways in recent times. Before product marketing as digitally, marketers should make strategies about digital marketing. With that, content and social media also play crucial roles for product endorsement. For all these, make primary focused on customer-company interaction through digital means [13-14].
Some common criteria need to set today for digital marketing such as span internet up to remote villages, make an improvement over internet speed, make cost effective hardware equipment etc. to see its impact in future. At recent times need to take a suitable step to promote digital products, then future would be bright and use by the semi-literate peoples. For this, public-private partnership plays significant roles to reach digital equipment among common peoples [15].

The different challenges confronting for digital marketing such as internet cost, not availability of efficient hardware equipment, not knowing about digital application etc. For all these, e-business technology environment need to be set up with the help of private organization by the government. In addition of these, at recent times digital marketing strategies seem inefficient. If proper strategies would not take then the digital marketing would not be fostering further [16].

As per Massachusetts Institute of Technology studies, a human brain can process an image for thirteen seconds only. In other words, image impact retains up to thirteen seconds on a human mind. After that, image impact on a human mind gets exponentially reduced. On such condition infographics and gifs images play a significant role to know more about company product. Through that, a customer knows about company products as well as visitors know what the content want to convey us [17-20].

\section{Image-based marketing by Facebook}

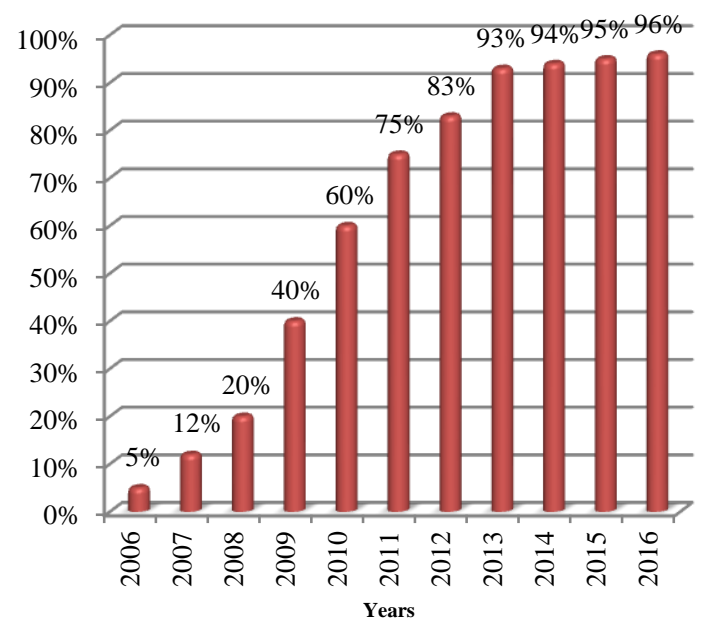

Fig.4. Image-based marketing in Social Platform like Facebook

In recent year, various types of image-based social media platforms have been developed as Pinterest, Instagram, Vine etc. However, these image-based social platforms have not been gained much popularity as Facebook and Twitter gained the popularity for imagebased marketing [21-23]. The Facebook and Twitter particularly focused on traditionally text-based social media platforms. These two platforms have gained much popularity than Pinterest, Instagram, and Vine. As we know that, most of the users used the Facebook and Twitter to post pictures. For the same reason, we can 
state that Facebook and Twitter filled with more and more pictures [24] (fig. 4).

\section{Methodology}

Primary data has been collected by personal visit, telephone interview, an online questionnaire about image-based marketing strategies and planning. The following questions have been included for taking feedback about image-based marketing:

a) How would online images be beneficial for a judge product?

b) How would the image support make differentiation about product quality and its quantity?

c) Which strategies should be adopted by firms for developing a digital image for marketing?

d) What extent website should be changed and which portion would be useful for a website and which portion would not useful for a website?

e) Is sufficient bandwidth being existed for displaying images in fast handheld devices? If it is so, then that handheld device is Internet-enabled or not.

f) Should change the images as per aspect ratio of display devices compatibility?

These questions and others had been circulated through online or make conversation through telephonically, personal, indirectly for taking feedback. The sample data has been collected around 100 company manager or marketing related personnel (Table 1).

Table. 1 Sample Data Collection from Different Firms about ImageBased Marketing

\begin{tabular}{|l|r|}
\hline Business Sector & $\mathbf{N}(\%)$ \\
\hline Manufacturing & $10(10 \%)$ \\
\hline Publishing Media/Internet/Online services & $50(50 \%)$ \\
\hline Accounting/Banking/Financial & $15(15 \%)$ \\
\hline Advertising/Communication/Marketing/PR & $25(25 \%)$ \\
\hline Size (by Employees) & $20(20 \%)$ \\
\hline Micro (fewer than 10 employees) & $40(40 \%)$ \\
\hline Small (10-50 employees) & $30(30 \%)$ \\
\hline Medium (50-250 employees) & $10(10 \%)$ \\
\hline Large (more than 250 employees) & $25(25 \%)$ \\
\hline Geographical Area & $25(25 \%)$ \\
\hline North India & $25(25 \%)$ \\
\hline South India & $25(25 \%)$ \\
\hline West India & $80(80 \%)$ \\
\hline East India & \\
\hline Job Title & \\
\hline CEO & \\
\hline Marketing Manager & \\
\hline
\end{tabular}

\section{MAJOR FINDING}

From above questionnaire, we have been received an appreciable amount of feedback regarding image-based marketing. Furthermore, received feedback has been divided into two parts: effective or not effective. From received feedback, we can state that most of the personnel are in favor of image-based product display, because, it attracts customers very quickly and its effect being present long-lasting in a consumer mind. Around $70 \%$ marketing personnel favor to concentrate more on image-based marketing rather than descriptive or traditional marketing. Analyzed data presented in Table 2.

Table. 2 Sample Data of Application of Image-Based Marketing in Indian Firms

\begin{tabular}{|l|l|}
\hline $\begin{array}{l}\text { Application of image-based marketing in } \\
\text { Indian firms }\end{array}$ & $\mathbf{8 0 \%}$ \\
\hline Rate & \\
\hline Very effective & $70 \%$ \\
\hline Effective & $15 \%$ \\
\hline Low effective & $5 \%$ \\
\hline Not at all effective & $10 \%$ \\
\hline
\end{tabular}

The social networking sites such as Facebook, Instagram, Twitter, Tumblr and other Apps and sites used images for promoting product among a mass of customers. The product can promote by creating the separate pages on the social networking sites. On analysis of different social networking sites, image-based marketing widely used by the Facebook, Instagram and others sites as $70 \%, 65 \%$, and $68 \%$ respectively. Others social networking site also march towards image-based marketing such as Twitter, LinkedIn, Tumblr etc. Obviously, Facebook and Instagram users are more than others social networking sites users. Hence, it would be appropriate to utilize fully all these for promotes firms products. In this medium not only image-based marketing promote products but also audio-video based product marketing exponentially growing. Furthermore, on analysis of fig. 5, Tumblr is completely far away about image-based marketing because Tumblr users are not in appreciable amount.

Online shopping portals are commonplace for best utilization of images for product endorsement. The ecommerce is growing more than traditional commerce. The reasons behind are that it is effective, efficient, transparent and time-saving. The e-commerce present in good position in developed countries such as America, France, Japan etc, whereas in developing countries ecommerce progress become appreciable such as China and India. In perspective of India, Homeshop18, Shopclues, Snapdeal, Myntra, Trendin, Jabong, Rediff, Flipkart, and Amazon are widely used for purchase products. Among these online shopping portals, Flipkart, Amazon and Snapdeal contributions are more than rest of online shopping portals in the field of e-commerce. The 
Flipkart use $90 \%$ consumers, after that we can placed Snapdeal and Amazon. If wants to attract consumers toward different product then image-based marketing played significant roles. For that, make a proper plan for capture images through the HD camera, after that upload on online shopping portals are the key to success for product marketing. In addition, small sized audio also attracts consumers towards purchase a particular product. Flipkart widely used that mechanism; hence, its share in e-commerce is more than rest of e-commerce portals (fig. $6)$.

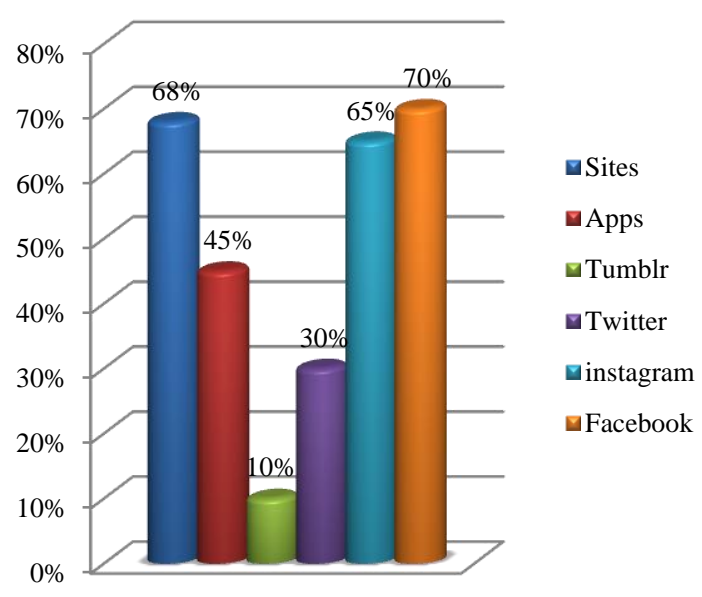

Fig.5. Social Networking site access for image-based marketing

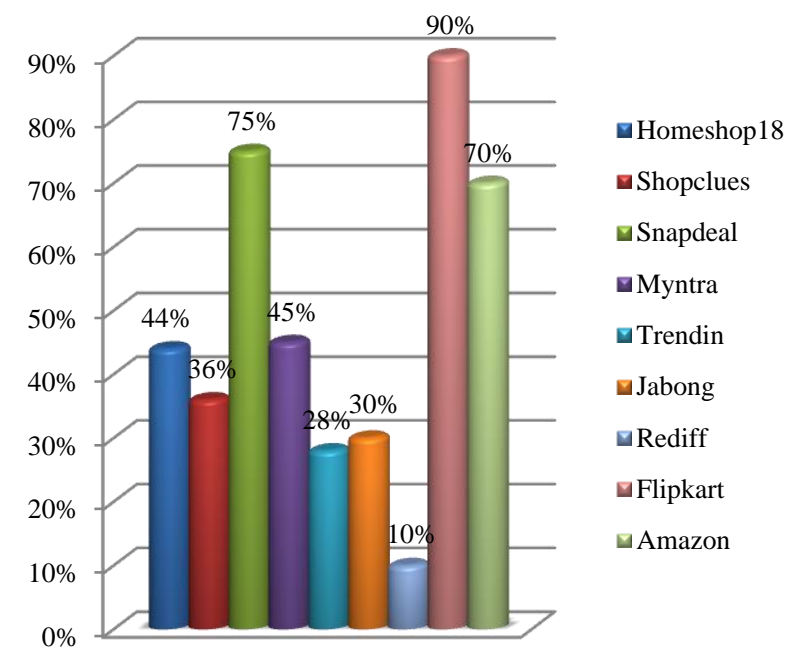

Fig.6. Online shopping sites contribution in image-based marketing

On other hands, choose alternative of above-mentioned marketing mechanisms such as SMS, Blog, Search Engine, Email and Content-based marketing. The SMSbased product endorsement is not appreciable when compared with other marketing paradigm. The primary reason is that consumers do not believe on product content rather they want to look either physically or relevant images. The SMS-based marketing is on such place where consumers have no time to visit nearest places for looking products as in physically. Furthermore, crucial advantage is that SMS forever placed into their inbox, whenever they find leisure time they open the SMS inbox and read sent messages. Even though, it is not an effective medium for product marketing. Hence, its contribution is not as in optimum point as others shown in fig. 6 (i.e. only 77\%). The email based marketing is effective because it is cost effective than endorsement of company products as prints media or television media. It is also environment-friendly. Due to these reasons, email can send to the selected group of peoples. Here selected group means send an email to those email users who are interested in particular products. Like and dislike by the customers could be collected by monitoring site visiting frequency and counter responses. Means, email is an appropriate medium for image-based marketing since through email we can send small sized images of the products. Subsequently, the search engine also contributes major share for marketing (i.e. $88 \%$ ). The indented consumers want to purchase particular products then first of all they search by a search engine and collect information regarding those products.

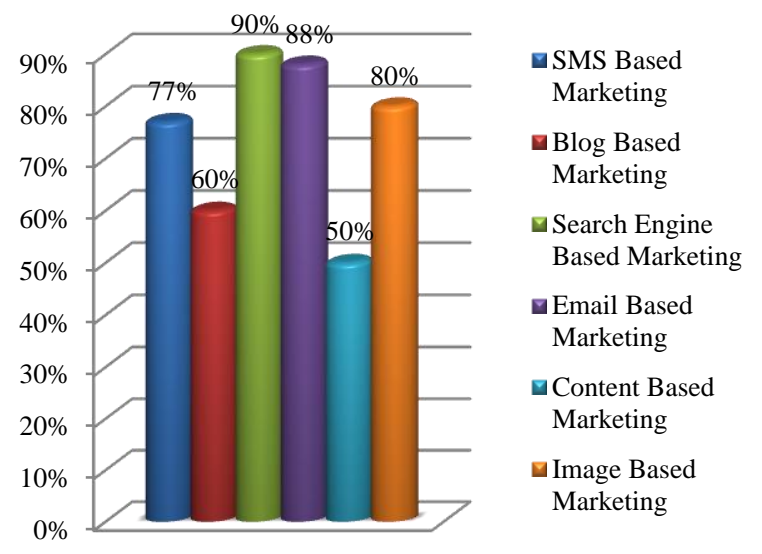

Fig.7. Digital marketing sources and online image based share in marketing field

\section{CONCLUSION}

It is a big mistake if we underestimate the roles of visuals in the digital marketing. The images, video make beneficial to a company by converting actual customers into forever customers or potential customers. There are numbers of social media websites which are used the images as well as video-sharing, unbelievably reaches to common people which will be prospect customers in future. We can reach to millions of peoples within a fraction of second by social media sites, online shopping portal (i.e. e-commerce) or any online portals. It is common, cost effective, simple, concise, compatible, efficient medium available in recent times.

In a single picture consists thousands of words which is depend on user interpretation. Hence, be alert every time about image development and posting in an electronic world. A single mistake can make big 
disastrous in the marketing world. Every team members should have a clear and concise vision about digital marketing and they proceed with that goal for place firm in a prestigious place in this competitive world. So that, whenever set up on account of social media sites, online shopping portals, online reservation system etc. should have a clear vision and need coordination and cooperation among team members of a firm for place company in a top position in a digital marketing arena. At last but not least, image-based marketing communicate those messages which customers want.

\section{REFERENCES}

[1] Harrang, Jeffrey Paul, David B. Gibbons, and John M. Burnette. "Systems and methods for distribution of digital media content utilizing viral marketing over social networks." U.S. Patent Application No. 12/626,231.

[2] Bird, D. (2007). Commonsense direct \& digital marketing. Kogan Page Publishers.

[3] Vishwanathan, Kumar K., Prakash R. Iyer, and Rangamani Sundar. "Methods for Marketing Digital Content to Mobile Communication Device Users." U.S. Patent Application No. 11/626,493.

[4] Kotorov, Radoslav. "Peer-to-peer marketing business method for telecommunication devices with digital displays." U.S. Patent Application No. 10/905,518.

[5] Mulhern, F. (2009). Integrated marketing communications: From media channels to digital connectivity. Journal of marketing communications, 15(2-3), 85-101.

[6] Murray, S. (2008). Digital images, photo-sharing, and our shifting notions of everyday aesthetics. Journal of Visual Culture, 7(2), 147-163.

[7] Edelman, D. C. (2010). Four ways to get more value from digital marketing. McKinsey Quarterly, 6.

[8] Bandaru, M. K., Siegel, R. E., Mogal, J., Agarwal, N., \& Lee, V. (2003). U.S. Patent No. 6,535,228. Washington, DC: U.S. Patent and Trademark Office.

[9] Rowley, J. (2008). Understanding digital content marketing. Journal of marketing management, 24(5-6), 517-540.

[10] Chi, Hsu-Hsien. "Interactive digital advertising vs. virtual brand community: Exploratory study of user motivation and social media marketing responses in Taiwan." Journal of Interactive Advertising 12.1 (2011): 44-61.

[11] Dholakia, U., \& Bagozzi, R. P. (2001). Consumer behavior in digital environments. Digital marketing, 163200.

[12] Chaffey, D., Smith, P. R., \& Smith, P. R. (2012). eMarketing eXcellence: Planning and optimizing your digital marketing. Routledge.

[13] Ryan, D. (2016). Understanding digital marketing: marketing strategies for engaging the digital generation. Kogan Page Publishers.
[14] De Sáez, E. E. (2002). Marketing concepts for libraries and information services. Facet Pub.

[15] Parsons, A., Zeisser, M., \& Waitman, R. (1998). Organizing today for the digital marketing of tomorrow. Journal of Interactive Marketing, 12(1), 31-46.

[16] Wind, Y. J., \& Mahajan, V. (2002). Digital marketing: global strategies from the world's leading experts. John Wiley \& Sons.

[17] Wang, Y. S., \& Tang, T. I. (2003). Assessing customer perceptions of website service quality in digital marketing environments. Journal of Organizational and End User Computing (JOEUC), 15(3), 14-31.

[18] Wind, J., \& Mahajan, V. (2002). Digital marketing. Symphonya. Emerging Issues in Management, (1), 43-54.

[19] Braudaway, G. W., Magerlein, K. A., \& Mintzer, F. C. (1996). U.S. Patent No. 5,530,759. Washington, DC: U.S. Patent and Trademark Office.

[20] Miller, M. (2012). B2B digital marketing: Using the web to market directly to businesses. Que Publishing.

[21] Weber, L. (2009). Marketing to the social web: How digital customer communities build your business. John Wiley \& Sons.

[22] Murray, P. N. (2000). U.S. Patent No. 6,061,659. Washington, DC: U.S. Patent and Trademark Office.

[23] Balogh, A., Blejer, H., Chen, E., Flank, S., Iannacone, C., Maloney, J., \& Lorton, M. (1996). U.S. Patent No. $5,493,677$. Washington, DC: U.S. Patent and Trademark Office.

[24] "Photos Make Up 93\% of The Most Engaging Posts on Facebook!" http://www.socialbakers.com/blog/1749photos-make-up-93-of-the-most-engaging-posts-onfacebook/

\section{Authors' Profiles}

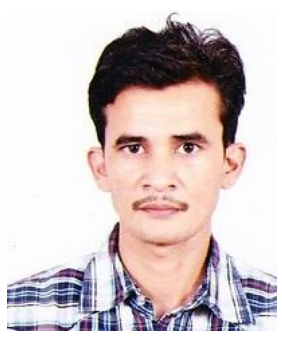

Shyam R. Sihare is the $\mathrm{Ph}$. D. candidate in Raksha Shakti University, Ahmedabad, India. He took up his Master's degree in Computer Science at Nagpur University, Nagpur, India in 2003 and obtained M. Phil. in Computer Science at Madurai Kamraj University, Madurai, India. He cleared Professor Eligibility Test GSLET, Gujarat, India in 2011. He obtained MCA at IGNOU, New Delhi, India in 2011.

$\mathrm{He}$ is currently working as Asstt. Professor in Computer Science and Application in Dr. APJ Abdul Kalam Govt. College, Silvassa, Dadra \& Nagar Haveli(UT), India. His research interests include Quantum Computer, Quantum Algorithms, Quantum Cryptography, and Classical Computer Algorithms.

How to cite this paper: Shyam R. Sihare, " Image-based Digital Marketing", International Journal of Information Engineering and Electronic Business(IJIEEB), Vol.9, No.5, pp. 10-17, 2017. DOI: 10.5815/ijieeb.2017.05.02 